\title{
Outcome of high-risk neonates with congenital complete heart block paced in the first 24 hours after birth
}

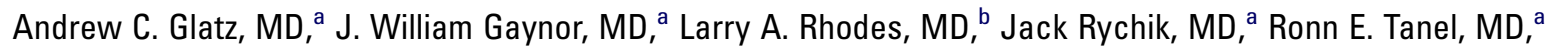
Victoria L. Vetter, MD, ${ }^{a}$ Jonathan R. Kaltman, MD, ${ }^{c}$ Susan C. Nicolson, MD, ${ }^{a}$ Lisa Montenegro, MD, ${ }^{a}$ and Maully J. Shah, MBBS ${ }^{a}$

Earn CME credits at http:// cme.ctsnetjournals.org
From The Children's Hospital of Philadelphia, The University of Pennsylvania School of Medicine, Philadelphia, $\mathrm{Pa}^{\mathrm{a}}$; the West Virginia University School of Medicine, Morgantown, $\mathrm{WVa}^{\mathrm{b}}$; and the Children's National Medical Center, Washington, DC. ${ }^{c}$

Received for publication Oct 2, 2007; revisions received Feb 5, 2008; accepted for publication April 11, 2008.

Address for reprints: Andrew C. Glatz, MD The Children's Hospital of Philadelphia, 2nd Floor, Main Building, 34th St and Civic Center Blvd, Philadelphia, PA 19104-4399 (E-mail: glatz@email.chop.edu).

J Thorac Cardiovasc Surg 2008;136:767-73 0022-5223/\$34.00

Copyright $(2008$ by The American Association for Thoracic Surgery

doi:10.1016/j.jtcvs.2008.04.019
Objective: Risk factors for poor outcome with congenital complete heart block include prematurity, low birth weight, hydrops, low ventricular rates, and congenital heart disease. In this group, medical therapy is often ineffective, pacing is technically challenging, and mortality exceeds $80 \%$. The purpose of this study is to assess outcomes of patients with congenital complete heart block who were paced in the first 24 hours after birth owing to the presence of known risk factors.

Methods: We performed a retrospective review of patients with congenital complete heart block paced in the first 24 hours after birth at our institution between November 1, 1995, and July 31, 2007.

Results: Thirteen patients were identified, 4 of whom had heterotaxy syndrome. Eleven patients had temporary epicardial pacing wires placed; 2 received permanent pacemakers as the initial mode of pacing. There were 7 deaths (54\% mortality) at a mean age of $19.9 \pm 19$ days. Among 7 patients with structural heart disease, there was 1 survivor. Among 6 patients with structurally normal hearts, there were 5 survivors $(P=.025)$. Patients with temporary wires who survived to permanent pacemaker implantation (6/11) used their temporary leads for $33.8 \pm 18.3$ days.

Conclusions: In the severely affected fetus with congenital complete heart block and significant structural heart disease, outcomes remain poor; however, neonates with congenital complete heart block and structurally normal hearts who are monitored antenatally and delivered in a planned fashion at an institution capable of early pacing can have favorable outcomes. The use of temporary pacing wires is an option in the management of these patients.

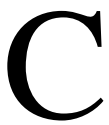

ongenital complete heart block (CCHB) is estimated to occur in 1 of every 15,000 to 22,000 live births, ${ }^{1,2}$ with $25 \%$ to $33 \%$ of cases associated with congenital heart disease. ${ }^{3}$ Historically, CCHB was thought to be a relatively benign condition, with the only significant morbidity being the need for pacemaker implantation to guard against the risk of Stokes-Adams attacks and sudden cardiac death. ${ }^{1,4,5}$ These diagnoses were typically made many months or even years after birth, when outcome is generally favorable. ${ }^{6}$ Clinical presentation of CCHB in utero or in the neonatal period represents a more lethal condition, with overall mortality in those with structurally normal hearts estimated at $19 \%$ to $31 \% .^{7,8}$ In the presence of associated congenital heart disease, outcome is even worse. ${ }^{9}$ Identified risk factors for poor outcomes in prenatally diagnosed CCHB include the presence of hydrops, ${ }^{10,11}$ low ventricular rate (usually defined as $<55$ beats $/ \mathrm{min}$ ), ${ }^{9,12,13}$ and prematurity, ${ }^{7}$ making this a different clinical entity from the historical descriptions. In affected newborns with the aforementioned risk factors, mortality may exceed $80 \%,{ }^{13,14}$ prompting some authors to argue for a new definition of CCHB based on early age at diagnosis. ${ }^{15}$

The purpose of this study was to report the experience at our institution with pacing in the first 24 hours after birth for high-risk infants born with CCHB, including the use 


\section{Abbreviations and Acronyms}

$\mathrm{CCHB}=$ congenital complete heart block

of temporary epicardial pacing wires as a staged approach to permanent pacing. Pacing in the first 24 hours after birth is performed at our institution for CCHB in the setting of compromised cardiac output or if there are indications for impending circulatory collapse. Prenatally, these signs include hydrops, ventricular dysfunction, very low fetal heart rates ( $<45$ beats/min), or fetal echocardiographic evidence of impending ventricular decompensation. Postnatally, ongoing metabolic acidosis despite optimal medical management prompts early pacing. Thus, inclusion of only those patients paced during this time window ensures that our study population would include the highest-risk subgroup of patients with CCHB.

\section{Methods}

\section{Study Population}

Study patients were identified from our institutional surgical database. Entry criteria were the diagnosis code of congenital heart block or third-degree atrioventricular block with either permanent or temporary pacemaker implantation in the first 24 hours after birth between November 1, 1995, and July 31, 2007. Patients were excluded if heart block occurred as a result of a separate surgical procedure. Our electrocardiographic database was queried to ascertain the total number of patients with a diagnosis of CCHB in the immediate newborn period.

\section{Study Protocol}

The medical records of the identified patients were retrospectively reviewed. Data reviewed included prenatal records, inpatient records including the specifics of the delivery, and outpatient records. A database was created to include the following patient characteristics: gender, gestational age at diagnosis, fetal echocardiographic findings (structural anatomy, heart rate, ventricular function, associated hydrops), fetal treatment, fetal course, maternal antibody status (if known), gestational age at delivery, birth weight, heart rate at birth, clinical course at birth, first postnatal echocardiogram, indication for pacing in the first 24 hours, type of pacemaker implanted, and clinical course after pacemaker implantation (duration of use of temporary leads, pacemaker complications/side effects).

\section{Surgical and Pacemaker Considerations}

In our study group, 2 patients had permanent pacing systems as the initial pacing modality. In both cases, the pacemaker was a Medtronic Thera SR 8960i with a single epicardial ventricular lead set in the VVI mode (Medtronic, Inc, Minneapolis, Minn). The pacemaker was placed in a subrectus pocket in an abdominal location. The remaining 11 patients had surgical placement of temporary epicardial leads. Three to 4 temporary pacing wires were affixed to the ventricular epicardial surface via either a small subxiphoid or anterior chest incision. A median sternotomy approach was used if additional temporary atrial pacing wires were implanted.
The wires were then brought to the skin surface and sutured in place. In all cases, 1 to 2 skin leads were also sutured in place. Epicardial wires were tested to ensure adequate pacing thresholds.

\section{Planned Early Pacing}

In 8 of our patients, pacing was performed in a planned fashion. These patients were all monitored closely through the Fetal Heart Program at The Children's Hospital of Philadelphia. On the basis of prenatal findings that placed them in a high-risk subset, these infants were delivered via scheduled cesarean section and then ventricular pacing was initiated via temporary epicardial wires immediately after birth. To implement this, a pediatric cardiovascular team consisting of a pediatric cardiothoracic surgeon, cardiac anesthesiologist, electrophysiologist, echocardiographer, and cardiac surgery nurses were present at the time of delivery of the infant for prompt evaluation, resuscitation, and treatment, which included placement of umbilical lines, anesthetizing the patient, and intubation followed by placement of the temporary leads as described earlier.

\section{Statistical Considerations}

Summary data were reported as frequencies, medians with ranges, and means with standard deviations where appropriate. Differences between groups (survivors vs nonsurvivors) were evaluated by either $t$ test for quantitative variables or log rank for dichotomous variables. Survival rates were assessed by Kaplan-Meier curves.

The Institutional Review Board of The Children's Hospital of Philadelphia approved this retrospective study and granted a waiver of informed consent.

\section{Results}

Between November 1, 1995, and July 31, 2007, a total of 24 patients were identified with the diagnosis of CCHB at birth or earlier. Of these 24 patients, 13 (54\%) received pacing in the first 24 hours after birth. Indications for pacing in these 13 patients included hydrops $(6 / 13,46 \%)$, profound fetal bradycardia $(<45$ beats/min) $(3 / 13,23 \%)$, severe intrauterine growth retardation $(1 / 13,8 \%)$, and refractory low cardiac output after birth $(3 / 13,23 \%)$.

Clinical characteristics of our patient population are summarized in Table 1. There were 4 boys and 9 girls. In 2 patients the diagnosis of CCHB was made at the time of birth; in the remaining 11 patients the diagnosis was made prenatally at gestational ages ranging from 18 to 30 weeks (mean $33 \pm 3.8$ weeks). Birth weights ranged from 990 to $4000 \mathrm{~g}$ (mean $1953 \pm 903 \mathrm{~g}$ ). Seven (54\%) patients had significant structural heart disease, including heterotaxy with atrioventricular canal $(3 / 7,43 \%)$, heterotaxy with total anomalous pulmonary venous connection $(1 / 7,14 \%)$, double-outlet right ventricle $(1 / 7,14 \%)$, hemodynamically significant patent ductus arteriosus with sinus venosus type atrial septal defect $(1 / 7,14 \%)$, and multiple ventricular septal defects with a spongiform myocardium $(1 / 7,14 \%)$. Of the 7 patients with structural heart disease, $3(43 \%)$ represented a form of single-ventricle physiology. Two of 13 (15\%) patients had permanent pacemakers placed at birth, and the remaining 11 had temporary pacing wires used as their initial 
TABLE 1. Clinical characteristics of patients with congenital complete heart block who were paced in the first 24 hours after birth

\begin{tabular}{|c|c|c|c|c|c|c|c|c|c|c|c|}
\hline Pt. & Sex & $\begin{array}{c}\text { GA at } \\
\text { diagnosis }\end{array}$ & $\begin{array}{c}\text { GA } \\
\text { at birth }\end{array}$ & $\begin{array}{l}\text { Birth } \\
\text { wt (g) }\end{array}$ & $\begin{array}{l}\text { Type } \\
\text { of PM }\end{array}$ & $\begin{array}{c}\text { Pacing } \\
\text { indication }\end{array}$ & $\begin{array}{c}\text { Mode } \\
\text { of pacing }\end{array}$ & $\begin{array}{c}\text { Structural } \\
\text { heart disease }\end{array}$ & $\begin{array}{c}\text { Days } \\
\text { w/TemP }\end{array}$ & Outcome & Cause of death \\
\hline 1 & $M$ & 28 & 30 & 1300 & Perm & Hydrops & VVI & $\begin{array}{l}\text { PDA, SVASD, trisomy } \\
\quad 21\end{array}$ & NA & Death & $\begin{array}{l}\text { Pulmonary } \\
\text { hypertensive crisis }\end{array}$ \\
\hline 2 & $\mathrm{~F}$ & Prenatal & 34 & 2630 & Perm & Hydrops & VVI & Heterotaxy, TAPVC & NA & Death & $\begin{array}{l}\text { Hypotension, } \\
\text { anasarca, } \\
\text { support withdrawn }\end{array}$ \\
\hline 3 & $\mathrm{~F}$ & Birth & 29 & 990 & Temp & $\mathrm{HR}<45$ & VVI & $\begin{array}{l}\text { Heterotaxy, } \\
\text { transitional AVC }\end{array}$ & 26 & Death & $\begin{array}{l}\text { Premature lung } \\
\text { disease, renal } \\
\text { insufficiency, low } \\
\text { cardiac output }\end{array}$ \\
\hline 4 & $\mathrm{~F}$ & 19 & 30 & 1859 & ${ }^{*}$ Temp & Hydrops & VVI & $\begin{array}{l}\text { Heterotaxy, } \\
\text { unbalanced AVC }\end{array}$ & 42 & Death & $\begin{array}{l}\text { Anasarca, SIRS, } \\
\text { sepsis, MOSF, } \\
\text { support withdrawn }\end{array}$ \\
\hline 5 & $\mathrm{~F}$ & 30 & 37 & 4000 & Temp & Hydrops & DDD & DORV & 0 & Death & $\begin{array}{l}\text { ventricular fibrillation } \\
\text { arrest }\end{array}$ \\
\hline 6 & $M$ & Birth & 26 & 1282 & Temp & $\begin{array}{l}\text { Low cardiac } \\
\text { output }\end{array}$ & DDD & Normal & 1 & Death & $\begin{array}{l}\text { Hypotension, Grade IV } \\
\text { ICH, support } \\
\text { withdrawn }\end{array}$ \\
\hline 7 & $\mathrm{M}$ & 24 & 39 & 2945 & Temp & $\begin{array}{l}\text { Low cardiac } \\
\text { output }\end{array}$ & VVI & $\begin{array}{l}\text { Heterotaxy, } \\
\text { transitional AVC }\end{array}$ & 20 & Death & $\begin{array}{l}\text { MOSF, support } \\
\text { withdrawn }\end{array}$ \\
\hline 8 & $\mathrm{~F}$ & 30 & 38 & 2900 & ${ }^{*}$ Temp & $\mathrm{HR}<45$ & VVI & Normal & 18 & Alive & \\
\hline 9 & $\mathrm{~F}$ & 22 & 31 & 1200 & ${ }^{*}$ Temp & Hydrops & VVI & $\begin{array}{l}\text { VSDs, spongy } \\
\text { myocardium }\end{array}$ & 67 & OHT, alive & \\
\hline 10 & $M$ & 22 & 34 & 1180 & ${ }^{*}$ Temp & $\begin{array}{l}\text { IUGR, } \\
\qquad \mathrm{HR}<45\end{array}$ & VVI & Normal & 36 & Alive & \\
\hline 11 & $\mathrm{~F}$ & 18 & 33 & 1500 & ${ }^{*}$ Temp & Hydrops & VVI & Normal & 34 & Alive & \\
\hline 12 & $\mathrm{~F}$ & 2nd trim & 34 & 1700 & ${ }^{*}$ Temp & $\mathrm{HR}<45$ & VVI & Normal & 16 & Alive & \\
\hline 13 & $\mathrm{~F}$ & 23 & 32 & 1900 & ${ }^{*}$ Temp & $\mathrm{HR}<45$ & VVO & Normal & 32 & Alive & \\
\hline
\end{tabular}

$G A$, Gestational age; $P M$, pacemaker; TemP, Temporary pacing leads; $P D A$, patent ductus arteriosus; $S V A S D$, sinus venosus atrial septal defect; TAPVC, total anomalous pulmonary venous connection; $A V C$, atrioventricular canal; SIRS, systemic inflammatory response syndrome; MOSF, multiorgan system failure; $D O R V$, double-outlet right ventricle; $H R$, heart rate; IUGR, intrauterine growth retardation; ICH, intracranial hemorrhage; VSD, ventricular septal defect, $O H T$, orthotopic heart transplant; $N A$, not applicable. ${ }^{*}$ Temporary wires placed in a planned manner immediately after scheduled delivery.

modality of pacing. Two of 11 patients with temporary pacing wires also had additional atrial epicardial wires implanted.

Early pacing was planned in 8 patients and was initiated soon after birth. In 4 patients, delivery of the infant via cesarean section was performed at The Children's Hospital of Philadelphia and the infant was immediately taken to an adjacent operating room for implantation of temporary pacing wires. In another 2 patients, the pediatric cardiovascular team set up an operating station in the delivery room of the affiliated adult hospital and temporary pacing was initiated soon after birth. In the remaining 2 patients, the infants were transported immediately after birth at the affiliated adult hospital to The Children's Hospital of Philadelphia cardiac surgical suite for temporary pacing.

The 5 patients who did not receive pacing wires immediately after birth all had a trial of medical therapy in the cardiac intensive care unit. This included mechanical ventilation, inotropic support, optimization of acid/base status, and an isoproterenol (Isuprel) infusion for rate support. Because of ongoing difficulties supporting adequate cardiac output, these patients had pacing wires placed within the first 24 hours after birth.

At the time of initial pacemaker implantation, there were no other surgical procedures performed, with the exception of ligation of a patent ductus arteriosus in 1 patient. There were 7 deaths at an average age of $19.9 \pm 19$ days for an overall mortality rate of $54 \%$. There were no intraoperative deaths. Causes of death included ventricular fibrillation arrest $(\mathrm{n}=1)$, pulmonary hypertensive crisis $(\mathrm{n}=1)$, and refractory heart failure $(\mathrm{n}=5)$ (see Table 1 for more details about causes of death). Of the 7 patients with significant structural heart disease, the sole survivor was a patient with multiple ventricular septal defects and a spongy myocardium. This patient ultimately underwent cardiac transplantation. Among the subgroup with single-ventricle physiology, mortality was $100 \%$ (3/3 patients). Among the 6 patients with structurally normal hearts, there was 1 death. A Kaplan-Meier survival 


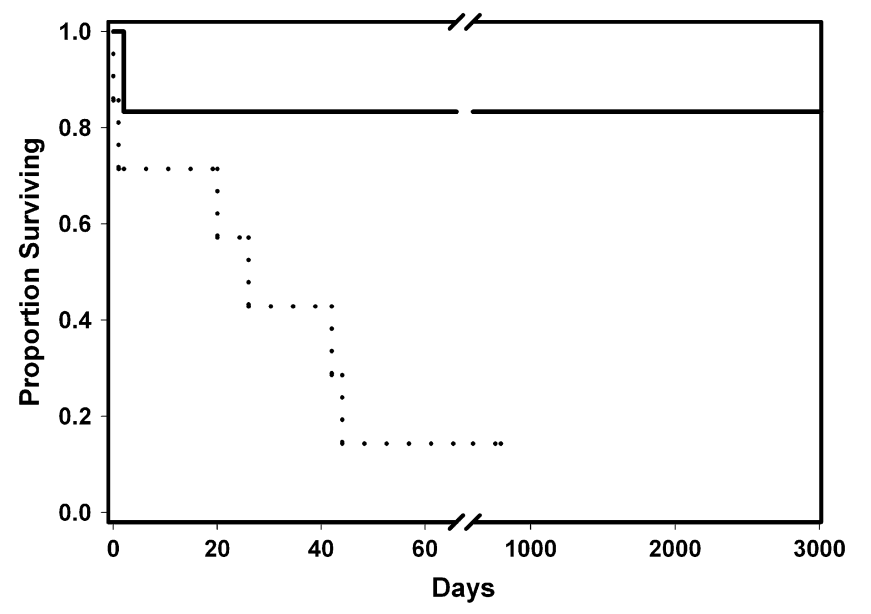

- Patients with no Heart Disease

- Patients with Heart Disease

Figure 1. Kaplan-Meier survival curve for patients with congenital complete heart block paced in the first 24 hours after birth both with $(n=7)$ and without $(n=6)$ structural heart disease $(P=.025)$.

curve comparing patients with and without structural heart disease is shown in Figure 1.

There was no statistically significant difference between survivors and nonsurvivors in gestational age at birth or birth weight (Table 2). All survivors eventually received permanent pacemakers. Survivors used their temporary pacing leads for as long as 67 days (mean $33.8 \pm 18.3$ days). All survivors are doing well at maximum follow-up of 10.9 years (mean $5.2 \pm 4.7$ years).

Table 3 summarizes the possible predictors of outcome assessed in our patient population. The presence of any form of structural heart disease was a significant predictor of mortality $(P=.025)$, while heterotaxy syndrome $(P=0.1)$ and single-ventricle heart disease $(P=.059)$ showed a trend toward worse outcome. Survival was significantly associated with the use of maternal steroids during pregnancy $(P=$ .004). A trend toward better outcome was seen in patients whose diagnosis was made antenatally $(P=.087)$ and in those in whom pacing was done in a planned manner immediately after birth on the basis of prenatal factors $(P=.065)$.

\section{Discussion}

Among patients with a prenatal diagnosis of $\mathrm{CCHB}$, there appear to be certain features that portend a particularly grave outcome. These include prematurity, low birth weight, low ventricular rate $(<55$ beats/min), significant structural heart disease, evidence for ventricular dysfunction or associated cardiomyopathy, and the presence of hydrops fetalis., ${ }^{7,-13}$ In the presence of hydrops, reported mortality rates for infants born with CCHB exceed $80 \%{ }^{13,14}$ In the most recent series, CCHB associated with structural heart disease con- tinues to have high mortality, whereas outcomes of prenatally diagnosed isolated CCHB seem to be much improved in the current era of aggressive prenatal and postnatal management. ${ }^{16}$ However, hydrops and cardiac enlargement remain risk factors for poor outcome. ${ }^{17}$

Antenatal treatment of CCHB has included (1) betasympathomimetics to increase the fetal heart rate $;^{11,18-20}$ (2) plasmapheresis $^{21}$ and steroids ${ }^{11,22,23}$ to target the antibodymediated and inflammatory component; and (3) digoxin ${ }^{12}$ and/or lasix ${ }^{24}$ to treat associated ventricular dysfunction and hydrops. Success with these therapies is largely anecdotal with no controlled clinical trials. There are also reports of unsuccessful attempts at direct fetal pacing. ${ }^{25}$ In the severely affected fetus, early delivery has been advocated. ${ }^{14}$ After birth, therapy typically includes aggressive medical management coupled with pacing in those infants who do not respond to medical therapies alone. There are significant technical challenges to placement of a permanent pacemaker in this group, inasmuch as these patients are often premature, small, and clinically unstable, although there are anecdotal reports of successful cases ${ }^{26-28}$ and a more recent report of a larger series in which permanent pacemakers were used in newborns with CCHB and a weight of at least $2.0 \mathrm{~kg} .{ }^{29}$ In an attempt to circumvent these challenges, the successful use of temporary pacing wires was reported in 2 cases by Deloof and associates ${ }^{30}$ and 2 cases by Weindling and colleagues. ${ }^{31}$ These cases support an argument for a staged approach to pacing in high-risk infants using temporary epicardial leads until the patient is large enough and stable enough for permanent pacemaker implantation.

Because of the poor outcomes and limited therapeutic options available, our institution has used the management approach of early pacing for the high-risk neonate with CCHB. As described in this study, this approach has evolved to pacing identified high-risk neonates immediately after birth. Planned early pacing of high-risk neonates with $\mathrm{CCHB}$ potentially reduces the adverse consequences of profound bradycardia and asystole soon after birth in the milieu of increasing metabolic demands. Along with the initiation of pacing soon after birth, central line placement and inotropic drug infusions, if necessary, are also started immediately, thus reducing the chances of hemodynamic lability during transport to the intensive care unit. Our own experience and that reported in the literature suggest a significant mortality in high-risk neonates with CCHB resulting from refractory low cardiac output. Once profound metabolic acidosis occurs, effective myocardial stimulation despite high output pacing may not be possible. All the neonates presented in this study had either significant findings of low cardiac output in utero or impending cardiovascular collapse soon after birth.

To date, this study represents the largest reported experience from a single institution with the use of pacing in the first 24 hours after birth for the high-risk infant with CCHB. In our experience, the survival for this high-risk 
TABLE 2. Comparison of quantitative variables between survivors and nonsurvivors of pacing in the first 24 hours after birth for patients with congenital complete heart block

\begin{tabular}{lcccc}
\hline & GA at birth (wk) & Birth weight (g) & $\begin{array}{c}\text { Duration of } \\
\text { temp leads (d) }\end{array}$ & Duration of follow-up (d) \\
\hline All patients & $32.9 \pm 3.8$ & $1953 \pm 903$ & $752 \pm 1375$ \\
Nonsurvivors & $32.3 \pm 4.7$ & $2144 \pm 1095$ & & $19.9 \pm 19.2$ \\
Survivors & $33.7 \pm 2.5$ & $1730 \pm 638$ & $33.8 \pm 18.3$ & $1911 \pm 1715$ \\
$P^{*}$ & NS & NS & &
\end{tabular}

Data are presented as mean \pm standard deviation. ${ }^{*} N S$, Not significant; statistical significance is taken as $P<.05$.

subgroup of infants with CCHB is $46 \%$ (6/13 patients). Although our mortality figures are lower than those reported in previous series, $\mathrm{CCHB}$ remains a potentially lethal condition. Overall, our population was fairly heterogeneous as described. There were no statistically significant differences between survivors and nonsurvivors on the basis of gestational age at delivery or birth weight, suggesting that these potential comorbidities do not play a significant role in affecting survival outcome in this population group.

We also compared survivors and nonsurvivors on the basis of a number of other clinical characteristics that might help predict which infants are at greater risk for poorer outcomes. Improved survival was associated with the use of maternal steroids, whereas the presence of structural heart disease was associated with worse outcome. The association between the use of steroids and improved outcome may be confounded by the fact that steroids are typically not used in cases of $\mathrm{CCHB}$ associated with structural heart disease, where the etiology of the heart block is not likely to be immune mediated. Nonetheless, there is recent evidence that steroid use does improve outcome in cases of isolated $\mathrm{CCHB},{ }^{32}$ so our practice is to treat the mothers of fetuses with isolated $\mathrm{CCHB}$ or antibody-associated CCHB with daily oral steroid (typically dexamethasone) from the time of diagnosis. Stress-dose steroids are given intravenously during labor, and then both mother and child are placed on a slow steroid taper regimen after birth. In addition, steroids are used in those pregnancies that require delivery of a premature infant to enhance fetal lung maturity, at the discretion of our colleagues in maternal and fetal medicine.

There was a trend toward improved outcome among those patients whose diagnosis was made antenatally and those whose delivery was planned followed by immediate pacing. Finally, there was a trend toward worse outcome in those patients with a form of heterotaxy syndrome or single-ventricle heart disease.

Given the heterogeneity of our patient population, it is instructive to examine trends among certain subgroups. Among 7 patients with significant structural heart disease, there is a sole survivor who was bridged to transplant with temporary pacing wires. Among the 6 patients with structurally normal hearts, there was only a single death — an infant born at 26 weeks of gestation at an outside hospital who arrived at our institution profoundly acidotic. Thus, it appears that $\mathrm{CCHB}$ paired with significant structural heart disease approaches uniform mortality, whereas neonates with CCHB and structurally normal hearts who are monitored closely antenatally and delivered in a planned fashion at an institution capable of early pacing can have favorable outcomes.

Two of our patients received permanent pacemakers as their initial pacing modality, the last in 1999. Both of these patients died. Since then, it has been our consistent approach to use temporary epicardial pacing wires in the high-risk neonate with CCHB. When possible, we have followed these severely affected fetuses through the Fetal Heart Program at The Children's Hospital of Philadelphia and planned

TABLE 3. Comparisons between groups of survivors and nonsurvivors of pacing in the first 24 hours after birth for congenital complete heart block based on a variety of clinical characteristics

\begin{tabular}{lccc}
\hline & $\begin{array}{c}\text { Survivors } \\
(\mathbf{n}=\mathbf{6})\end{array}$ & $\begin{array}{c}\text { Nonsurvivors } \\
(\mathbf{n}=\mathbf{7})\end{array}$ & $\boldsymbol{P}^{*}$ \\
\hline Antenatal diagnosis & 6 & 5 & .087 \\
Premature $(<36$ wk) & 5 & 5 & .429 \\
LBW $(<2 \mathrm{~kg})$ & 5 & 4 & .367 \\
Gender & 5 female & 4 female & .14 \\
Maternal steroids & 6 & 1 & .004 \\
Maternal $\beta$-agonists & 5 & 2 & .132 \\
Hydrops & 2 & 4 & .467 \\
Birth at 0 SH & 0 & 3 & .131 \\
CHD: 1 -vent & 0 & 3 & .059 \\
CHD: 2 -vent & 1 & 3 & .367 \\
CHD: heterotaxy & 0 & 4 & .109 \\
CHD: any form & 1 & 6 & .025 \\
Heart rate $<55$ beats/min & 6 & 7 & NA \\
Planned TemP & 6 & 2 & .065 \\
\hline
\end{tabular}

Numbers expressed are the incidence of the clinical characteristic occurring in each subgroup. $L B W$, Low birth weight; $O H S$, outside hospital; $C H D$, congenital heart disease; 1-vent, single ventricle; 2-vent, two ventricles; TemP, temporary pacing leads; $N A$, not available. ${ }^{*}$ Statistical significance is taken as $P<.05$. Bold faced values are those that reached statistical significance. Italic values are near significant (.05 and .1). 
a scheduled delivery followed by immediate placement of temporary epicardial wires for early pacing either in the delivery room or in an adjoining operating room. Eight patients have been treated through this planned approach to fetal surveillance, scheduled delivery, and immediate placement of temporary pacing wires. Among these patients, the only deaths occurred in 2 with significant structural heart disease. All patients with structurally normal hearts who were managed in this planned fashion survived to permanent pacing and remain alive today, despite fetal factors that would place them in a high-risk subset.

In total, 11 of our patients received temporary pacing leads as the initial mode of pacing. This approach obviates the immediate need to perform a larger-scale operation on a tenuous neonate. Our practice is to use three or four epicardial wires plus at least one skin wire to guard against increasing thresholds that may occur in any individual wire. In 1 patient, the leads had to be removed owing to infection at the site of skin entry. By this point, the patient's condition had stabilized to the point that he could be further managed with an isoproterenol infusion. In the other 10 patients, the leads were all technical successes and provided effective electrical pacing for up to $67(33.8 \pm 18.3)$ days.

Two patients in our series had temporary atrial pacing wires placed at the same time as the temporary ventricular wires. In 1 of these patients, there was significant hypotension associated with DDD pacing and 1:1 atrioventricular synchrony. When the post-ventricular atrial refractory period was lengthened to effectively produce 2:1 atrioventricular conduction, the blood pressure was significantly improved. It is our hypothesis that a sudden drastic increase in heart rate associated with DDD pacing and tracking of the atrial rate is not well tolerated in these neonates. Instead, it is our practice to initially pace in a VVI manner and slowly increase the ventricular rate to physiologic levels.

There have been two recent reports ${ }^{28,29}$ in the literature on the use of temporary pacing leads as a bridge to permanent pacing in a small number of patients. Our study is the largest to date that demonstrates that temporary pacing wires can be a technically feasible method of pacing the high-risk neonate with CCHB. All survivors in our patient population ultimately received permanent pacemakers and all are doing well at most recent follow-up (median duration of 2.2 years, range 0.2-10.9 years). Permanent pacemakers were implanted when patients reached a point of clinical stability and achieved a weight deemed suitable for a permanent pacing system (typically $>2 \mathrm{~kg}$ ).

Our study is limited by its retrospective nature and small sample size. We are only able to assess for associations between variables and outcomes and not causation. Also, maternal antibody status was not available in all patients with isolated CCHB. Further, there have been changes in management approaches that have occurred during the period of our review that may impart bias. Finally, these results reflect the experience of a single institution and may not necessarily generalize to other institutions.

In conclusion, the most severely affected infants with CCHB continue to have a high risk of mortality despite maximal medical and surgical care. In our experience, the coexistence of significant structural heart disease portends a particularly grave prognosis. However, in those with structurally normal hearts, there is reason for optimism even in the face of severe prematurity, low birth weight, in utero hypdrops, or ventricular dysfunction. In these patients, the use of temporary epicardial ventricular pacing wires implanted by a minimally invasive approach can be used successfully as a bridge to a permanent pacemaker.

Our recommended approach to the management of the fetus with CCHB includes early diagnosis, close fetal surveillance, and the use of maternal steroids in cases of isolated CCHB followed by planned delivery at an institution with the ability for early placement of temporary epicardial pacing leads for the severely affected newborn.

Xuemei Zhang, a senior biostatistician in the Biostatistics and Data Management Core of The Children's Hospital of Philadelphia, was instrumental in performing the statistical analysis for this study.

\section{References}

1. Michaelsson M, Engle MA. Congenital complete heart block: an international study of the natural history. Cardiovasc Clin. 1972;4: 85-101.

2. Reid JM, Coleman EN, Doig W. Complete congenital heart block. Report of 35 cases. Br Heart J. 1982;48:236-9.

3. Agarwala B, Sheikh Z, Cibils LA. Congenital complete heart block. $J$ Natl Med Assoc. 1996;88:725-9.

4. Pordon CM, Moodie DS. Adults with congenital complete heart block: 25-year follow-up. Cleve Clin J Med. 1992;59:587-90.

5. Sholler GF, Walsh EP. Congenital complete heart block in patients without anatomic cardiac defects. Am Heart J. 1989;118:1193-8.

6. Eronen M. Long-term outcome of children with complete heart block diagnosed after the newborn period. Pediatr Cardiol. 2001;22:133-7.

7. Buyon JP, Hiebert R, Copel J, Craft J, Friedman D, Katholi M, et al. Autoimmune-associated congenital heart block: demographics, mortality, morbidity and recurrence rates obtained from a national neonatal lupus registry. J Am Coll Cardiol. 1998;31:1658-66.

8. Waltuck J, Buyon JP. Autoantibody-associated congenital heart block: outcome in mothers and children. Ann Intern Med. 1994;120:544-51.

9. Schmidt KG, Ulmer HE, Silverman NH, Kleinman CS, Copel JA. Perinatal outcome of fetal complete atrioventricular block: a multicenter experience. J Am Coll Cardiol. 1991;17:1360-6.

10. Eronen M, Siren MK, Ekblad H, Tikanoja T, Julkunen H, Paavilainen T. Short- and long-term outcome of children with congenital complete heart block diagnosed in utero or as a newborn. Pediatrics. 2000; 106(1 Pt 1):86-91.

11. Maeno Y, Himeno W, Saito A, Hiraishi S, Hirose O, Ikuma M, et al. Clinical course of fetal congenital atrioventricular block in the Japanese population: a multicentre experience. Heart. 2005;91:1075-9.

12. Eronen M, Heikkila P, Teramo K. Congenital complete heart block in the fetus: hemodynamic features, antenatal treatment, and outcome in six cases. Pediatr Cardiol. 2001;22:385-92.

13. Groves AM, Allan LD, Rosenthal E. Outcome of isolated congenital complete heart block diagnosed in utero. Heart. 1996;75:190-4.

14. Jaeggi ET, Hamilton RM, Silverman ED, Zamora SA, Hornberger LK. Outcome of children with fetal, neonatal or childhood diagnosis of isolated congenital atrioventricular block. A single institution's experience of 30 years. J Am Coll Cardiol. 2002;39:130-7. 
15. Brucato A, Jonzon A, Friedman D, Allan LD, Vignati G, Gasparini M, et al. Proposal for a new definition of congenital complete atrioventricular block. Lupus. 2003;12:427-35.

16. Jaeggi ET, Hornberger LK, Smallhorn JF, Fouron JC. Prenatal diagnosis of complete atrioventricular block associated with structural heart disease: combined experience of two tertiary care centers and review of the literature. Ultrasound Obstet Gynecol. 2005;26:16-21.

17. Berg C, Geipel A, Kohl T, Breuer J, Germer U, Krapp M, et al. Atrioventricular block detected in fetal life: associated anomalies and potential prognostic markers. Ultrasound Obstet Gynecol. 2005;26:4-15.

18. Groves AM, Allan LD, Rosenthal E. Therapeutic trial of sympathomimetics in three cases of complete heart block in the fetus. Circulation. 1995;92:3394-6.

19. Novi JM, Mulvihill BH. Use of a subcutaneous beta-sympathomimetic pump for the treatment of fetal congenital complete heart block. A case report. J Reprod Med. 2003;48:893-5.

20. Yoshida H, Iwamoto M, Sakakibara H, Shigeta H, Hirahara F, Sato K. Treatment of fetal congenital complete heart block with maternal administration of beta-sympathomimetics (terbutaline): a case report. Gynecol Obstet Invest. 2001;52:142-4.

21. van der Leij JN, Visser GH, Bink-Boelkens MT, Meilof JF, Kallenberg CG. Successful outcome of pregnancy after treatment of maternal anti-Ro (SSA) antibodies with immunosuppressive therapy and plasmapheresis. Prenat Diagn. 1994;14:1003-7.

22. Copel JA, Buyon JP, Kleinman CS. Successful in utero therapy of fetal heart block. Am J Obstet Gynecol. 1995;173:1384-90.

23. Rosenthal D, Druzin M, Chin C, Dubin A. A new therapeutic approach to the fetus with congenital complete heart block: preemptive, targeted therapy with dexamethasone. Obstet Gynecol. 1998;92(4 Pt 2):689-91.
24. Anandakumar C, Biswas A, Chew SS, Chia D, Wong YC, Ratnam SS. Direct fetal therapy for hydrops secondary to congenital atrioventricular heart block. Obstet Gynecol. 1996;87(5 Pt 2):835-7.

25. Carpenter RJ Jr, Strasburger JF, Garson A Jr, Smith RT, Deter RL, Engelhardt HT Jr. Fetal ventricular pacing for hydrops secondary to complete atrioventricular block. J Am Coll Cardiol. 1986;8:1434-6.

26. Donofrio MT, Gullquist SD, Mehta ID, Moskowitz WB. Congenital complete heart block: fetal management protocol, review of the literature, and report of the smallest successful pacemaker implantation. J Perinatol. 2004;24:112-7.

27. Haas NA, Kulasekaran K, Camphausen C. Beneficial hemodynamic response of transthoracic cardiac pacing in a $2 \mathrm{~kg}$ preterm neonate. Intensive Care Med. 2005;31:877-9.

28. von Schnakenburg C, Fink C, Peuster M, Wessel A, VazquezJimenez JF. Permanent pacemaker implantation in a $1,445 \mathrm{~g}$ preterm neonate on the first day of life. Thorac Cardiovasc Surg. 2002;50:363-5.

29. Kelle AM, Backer CL, Tsao S, Stewart RD, Franklin WH, Deal BJ, et al. Dual-chamber pacing in neonates with congenital heart block. J Thorac Cardiovasc Surg. 2007;134:1188-92.

30. Deloof E, Devlieger H, Van Hoestenberghe R, Van den bK, Daenen W, Gewillig M. Management with a staged approach of the premature hydropic fetus due to complete congenital heart block. Eur J Pediatr. 1997; 156:521-3.

31. Weindling SN, Saul JP, Triedman JK, Burke RP, Jonas RA, Gamble WJ, et al. Staged pacing therapy for congenital complete heart block in premature infants. Am J Cardiol. 1994;74:412-3.

32. Jaeggi ET, Fouron JC, Silverman ED, Ryan G, Smallhorn J, Hornberger LK. Transplacental fetal treatment improves the outcome of prenatally diagnosed complete atrioventricular block without structural heart disease. Circulation. 2004;110:1542-8. 